stcep, is positive proof that the non-existence of extensive reefs cannot in such places be owing to any deleterious influences arising from volcanic action, but must be on account of the depth of water on the coast.

Upolu, Samoa

S. J. WHITMEE

\section{Mirage on Snowdon}

ON Monday, July I2, I, with a party, ascended Snowdon. The atmosphere was clear until we had reached within half a mile of the summit, when a light cloud rising stealthily from amongst the southern peaks enveloped it. Drifting towards us, when very near, the cloud dropped over the eastern shoulder of the mountain just where it dips towards Capel Curig. As we stood watching, great was our surprise and delight as we beheld painted upon it, not the arc-ent-cicl with which we are familiar, but a complete and brilliant prismatic circle, apparently about thirty feet in diameter, in the very centre of which we ourselves were depicted, the image being somewhat enlarged but clearly defined; as we arranged the party in groups, or bowed to each other, every form and movement was faithfully reproduced in the picture. It was now about $80^{\circ}$ clock, with the sun nearly in a line with as. Our guide, who had made some hundreds of ascents, had never witnessed such a sight before.

Fordfield, Cambridge

H. J. WETENHALL

\section{OUR ASTRONOMTCAL COLUMN}

KEPLER'S NOVA, I604,--We learn from Prof. Winnecke that, in consequence of the remarks upon this star which appeared in NATURE, vol. xi. p. 249, he has lately examined the neighbourhood, and, in addition to the star of 1 rizth magnitude there mentioned-the position of which for $185^{\circ} \circ$ he finds to be R.A. $17 \mathrm{~h} .22 \mathrm{~m} .4^{\circ} 6 \mathrm{~s}$., N.P.D. III $23^{\circ} 6^{\prime}$-he found one of 12 th magnitude in R.A. I7h. 2 Im. $49^{\prime} 3$ s., N.P.D. II $1^{\circ} 19^{\prime} 3^{\prime}$. This star agrees almost precisely in place with the roth magnitude marked upon No. 52 of Chacornac's charts, though not at present of that brightness; but we are able to state that in August $187 \mathrm{I}$ and June 1872 nothing was visible in this position in a telescope which would show stars to $13^{\circ} 14$ magnitude in Winnecke's scale. It will be desirable to watch this small star closely, as it is quite possible it might be identical with Kepler's famous star, the observed place of which is not so accurately known as in the case of the similar object obseryed by Tycho Brahe in 1572 . Prof. Winnecke, however, suggests that, as the star marked by Chacornac is just upon the margin of his map, where some distortion exists, it might possibly be identical with No. 16,872 of Oeltzen's Argelander, a star estimated 8.9 in the Bonn Zones; still the place of the Izth magnitude agrees much more closely with that of Chacornac's loth, read off from his chart as nearly as the circumstances permit. It may be well to compare the fainter star found by Prof. Winnecke, from time to time with the il't2th close at hand, and easily identified if the instrument be set for Argelander's star, which may be considered a bright $9^{\text {th }}$ magnitude.

THE BINARY STAR 4 AQUARM.--If good meastures of this star are practicable during the present season, an idea of the form of the orbit may perhaps be obtained. Dawes's series of epochs will be of material service in this respect ; without them, doubt might have been occasioned by the two discordant epochs of Mädler, which may have been owing to distorted images at low altitude. The object is certainly one of considerable difficulty, and really trustworthy measures are perhaps only to be expected from practised observers in command of instruments of excellent definition. In Barclay's second catalogue it is described as just elongated in the direction I $44^{\circ}$, with power 450 on the Io-inch refractor at Leyton, at the epoch 1865\%4; this angle shows direct progress, very much in accordance with Dawes's measures. Possibly the companion may now be found nearly due south of the primary.
THE NEBULA.-Prof. Schönfeld has published in Part II. of "Astronomische Beobachtungen zu Mannheim" Carlsruhe, 1875 -a continuation of the valuable series of observations commenced by him in 1860 , for accurate determination of the positions of a selected list of nebula. In this second part we have the places of 336 of these objects, obtained by direct reference to stars, which, as in the case of those employed in fixing the positions of the nebulæ included in the first part (Mannheim, I 862), have been meridionally determined at Bonn by the late Prof. Argelander; the mean places are found in Vol. vi. of the Bonn Observations. Schönfeld's epoch is as before, I $865^{\circ} \mathrm{O}$, for which year the precessions are computed with Bessel's constants, still preferred by many of the German astronomers. The differences from Schultz's Preliminary Catalogue are shown, and are generally small. As one result of more recent observations, it is remarked by Schönfeld that a sensible proper motion of the great nebula in Andromedre, which appeared to be indicated by a comparison of Flamsteed's observations with those of D'Agelet and Lalande, is not confirmed.

Prof. Adams, in his last address as President of the Royal Astronomical Society, remarks upon the great value attaching to Schönfeld's micrometrical observations of the nebula, of which we have here the continuation.

ENCKE'S COMET.-Mr. J. Tebbutt of Windsor, New South Wales, reports his discovery of a comet, which he supposed to be Encke's, on the morning of May 7 th, in the constellation Cetus. It is, we believe, the second occasion upon which this able amateur astronomer has detected this comet, before the arrival of an ephemeris from Europe, and no doubt in the present case his independent discovery, which he communicated telegraphically to the Government astronomers at Sydney and Melbourne, will lead to a number of observations for position at the Australian observatories, which might have been otherwise lost. The search for comets without the aid of an ephemeris is hardly an occupation which can be expected in a pubiic observatory, where time is valuable for routine work-hence an argument for the early and general publication of ephemerides-and an inducement for some amateurs, especially in southern latitudes where a great necessity for systematic sweeping of the sky in search of comets appears still to exist, to so employ their leisure time. One at least of the lost comets of short period, is far more likely to be recovered in the southern hemisphere, than in these latitudes.

The ARgentine Observatory.-Dr. Gould has just circulated in two small pamphlets, in English, the annual Report for 1874 of proceedings at the Observatory of Cordoba, and at the Meteorological Office, which has also been organised by this distinguished astronomer. With regard to astronomical work, the observations for the "Uranometry" are completed, as already mentioned in this column. The charts will be thirteen in number, including the whole of the scuthern heavens as well as the first ten degrees north of the equator, and about 8,500 stars will be represented upon them, of which about nine-tenths have southern declination. A catalogue will accompany the Atlas, as with the works of Argelander, Heis, and Behrmann. The zone-work was in a very forward state, 82,537 stars having been observed, and with the exception of an insignificant number of zones for which it might be necessary to wait till a later period of the year, Dr. Gould expected to complete this laborious undertaking by the end of last month. The third of the principal sub-divisions of work at Cordoba, the formation of what is called "the smaller Catalogue" is also well advanced : the catalogue is intended to consist of nearly 5,000 of the brighter stars of the southern heavens, each one observed not less than four times; in the year 1874, 12,500 observations of 3,600 different stars were made, the greater number during Dr. Gould's visit to his native city, a sufficient proof that he has been 